\title{
Study of the Drying Behavior of Resorcinol Formaldehyde Hydrogels : Experimental Investigation and Numerical Framework
}

\author{
J.Hubert ${ }^{1}$, E. Plougonven ${ }^{2}$, A. Leonard ${ }^{2}$ and F. Collin ${ }^{1}$ \\ ${ }^{1}$ University of Liège, Department ArGEnCo, Allée de la découverte 9, 4000 Liège, \\ Belgium; email: julien.hubert@ulg.ac.be \\ ${ }^{2}$ University of Liège, Department Chemical Engineering, Agora Quarter, 4000 Liège, \\ Belgium
}

\begin{abstract}
In this paper, we present the method used to investigate the drying behavior of the Resorcinol $(\mathrm{R})$ formaldehyde $(\mathrm{F})$ hydrogels and the tools needed for its numerical modeling. First, the studied material is introduced. Then the experiments are briefly presented and some preliminary results are given. Drying tests have been first carried out to characterize the drying kinetics of RF hydrogels. The experiments are used to calibrate the transfer parameters of a convective drying law based on the boundary layer model [Gerard et al. (2010)]. Ultimately, the goal is to model the Hydromechanical behavior of the RF gels during drying and predict crack genesis. To do so, a thermohydro-mechanical coupled model including a tensile failure criterion is suggested. The tensile failure criterion is based on the existence of a tension cut-off expressed in terms of a minimum mean effective stress.
\end{abstract}

\section{INTRODUCTION}

Production of carbon aerogels by $\mathrm{CO}_{2}$ supercritical drying of resorcinol (R) formaldehyde $(\mathrm{F})$ hydrogels followed by pyrolysis has been studied since their introduction by Pekala [Pekala (1989)]. Their large mesopore volumes and high specific surface areas make them interesting for many potential applications such as adsorbents for gas separation, catalysts supports, etc [Job (2006)]. Supercritical drying is not applicable at an industrial scale because of technical and safety reasons. Some other methods to produce an aerogel-like mesoporous texture have been tested and it has been shown that it is possible to produce porous resorcinolformaldehyde xerogels by using atmospheric convective drying [Job et al. (2006)]. Since crack-free monoliths are required, the hydraulic and mechanical properties of the RF hydrogels and their evolution with water content are essential to model their thermo-hydro-mechanical behavior during convective drying and avoid cracking. This paper aims at presenting the methods used to investigate the drying behavior of the RF hydrogels and at introducing the hydromechanical model which will be use to simulate it. 


\section{MATERIALS AND METHODS}

\section{Samples Preparation}

Hydrogels are prepared by polycondensation of resorcinol, solubilized in water, with formaldehyde, in the presence of $\mathrm{Na}_{2} \mathrm{CO}_{3}$. The $\mathrm{pH}$ of the precursors solution is achieved by changing the resorcinol/sodium carbonate molar ratio, R/C. The resorcinolformaldehyde molar ratio, $\mathrm{R} / \mathrm{F}$, and the dilution ratio, the solvent on resorcinol plus formaldehyde molar ratio, are fixed at 0.5 (stochiometric ratio), and 5.7, respectively. Cylindrical samples were obtained by casting solution into glass molds and putting them back in the water bath for gelation and aging during $24 \mathrm{~h}$ at $70^{\circ} \mathrm{C}$. A second cylindrical mold, slightly smaller in diameter, was slipped into the first one and put in touch with the solution so that the contact between air and liquid was avoided. Evaporation was prevented by a paraffin film covering both cylinders. This procedure aims at avoiding thermal inertia and temperature gradients during the gelation phase. Moreover, the size of the samples was adapted to both the convective dryer chamber and the microtomograph used to follow shrinkage and cracking during drying.

\section{Convective Drying Test}

After gelation and aging, the samples are dried in a classical convective dryer under controlled air relative humidity, temperature and velocity designed for small samples [Léonard (2003)]. The sample is allowed to dry on its whole external surface. The sample is weighed every $10 \mathrm{~s}$ during the drying test. The drying kinetics can be analyzed based on the weight measurements, which are used to plot Krischer's curve (Fig. 1a). It expresses the variation of the drying rate with water content. Krischer's curve is studied in parallel with the evolution of temperature with time (Fig. 1b). This is the behavior observed in the case where the drying air temperature is significantly higher than the sample initial temperature [Musielak et Jacek (2007)]. On Krischer's curve, three periods can be observed :

1. The preheating period (I) is very short and corresponds to an increase in drying rate. The temperature at the surface of the sample also increases from its initial value to the temperature of the wet bulb [Gerard et al. (2010)].

2. The Constant Rate Period (CRP) (II) appears at the beginning of the drying process. It is characterized by a constant drying rate. The heat supply is completely used for the evaporation of the liquid water at the surface of the sample and thus, the temperature remains constant and equal to the temperature of the wet bulb. The evaporation occurs in a saturated boundary layer. The vapor and the heat transfers are only influenced by the external conditions, i.e. the drying air temperature, relative humidity or velocity [Nadeau et Puiggali (1995)]. This period will last until the sample is no longer saturated and internal transfers start to influence the drying rate.

3. The Falling Rate Period (FRP)(III) is characterized by an increase in the dried body temperature from the wet bulb temperature to the drying fluid temperature. 
The drying rate decreases because of the decrease in permeability with the desaturation of the medium.

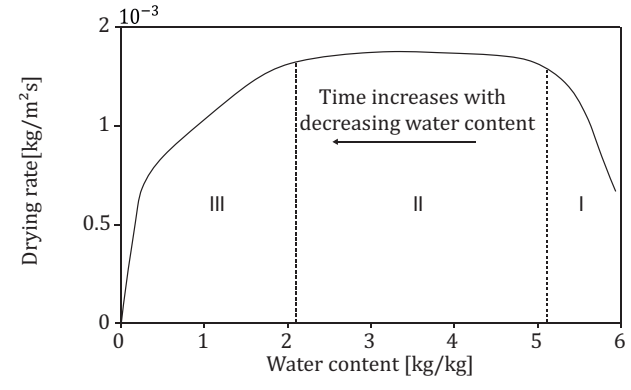

(a) Krischer's curve

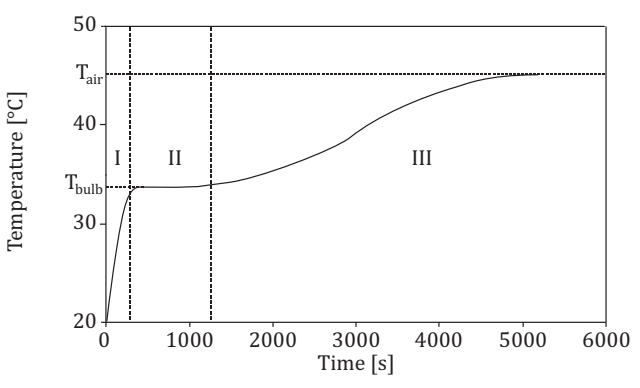

(b) Temperature evolution with time

Figure 1: Drying kinetics

\section{Microtomography}

X-ray microtomography, in combination with image analysis, has been proved to provide an accurate and non-destructive way to determine simultaneously shrinkage and crack extent. A methodology using X-ray microtomography coupled to image analysis was previously developed [Léonard et al. (2002)]. The sample is scanned before the drying test and every hour until complete stabilization of the sample mass (i.e. the end of the drying). For the tomographic acquisitions the samples had to be removed from the dryer. They are sealed during the whole process and the acquisition time has to be limited to avoid the relaxation of moisture profiles and further drying of the sample. This limits the number of projections.

\section{EXPERIMENTAL}

In this section, the preliminary results of our experimental investigation are presented.

\section{Elastic modulus}

Uniaxial compression tests were performed. The applied load and the displacements are measured. The loading rate was fixed at $0.4 \mathrm{~mm} / \mathrm{min}$. The test were performed on samples at different water content. The elastic modulus is the slope of the linear part of the graph of compressive stress versus strain (Fig. 2a). As can be seen, the initial slope of the curves increases with decreasing water content. This clearly exhibits a stiffening effect with decreasing water content as documented by Leonard et al [Léonard et al. (2008)]. This effect is also visible in Fig. 2b presenting the variation of the elastic modulus in function of the water content of the samples. Note that some of the samples tested could not be broken using our loading cell explaining the constant stress observed. 


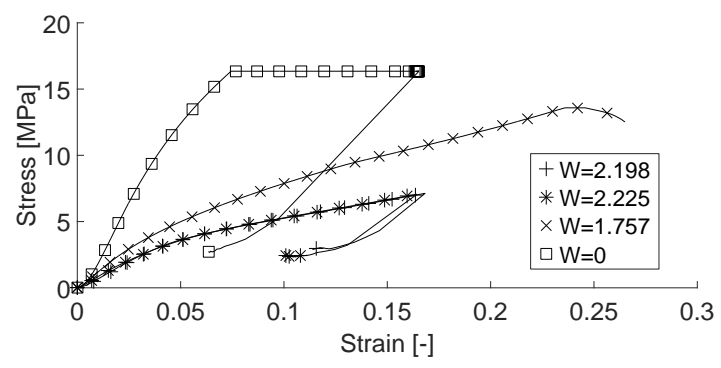

(a) Stress vs. strain curves

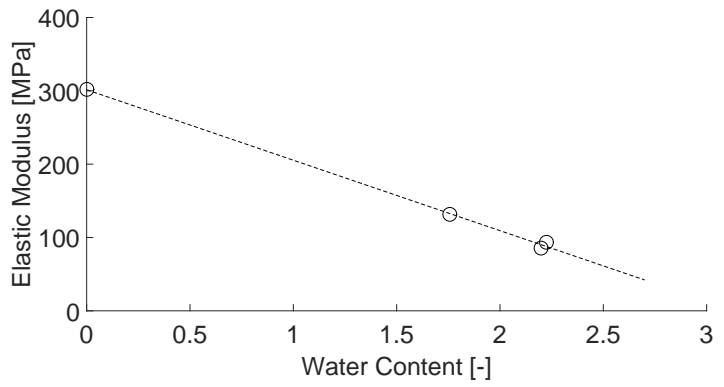

(b) Variation of elastic modulus with water content

Figure 2: Uniaxial loading tests results

\section{Tensile strength}

Brazilian test were performed to determine the tensile strength of the RF hydrogels. The loading rate was fixed at $0.2 \mathrm{~mm} / \mathrm{min}$. The evolution of the loading charge with time is visible in Fig. 3a. As can been seen, there is an increase of the maximum admissible load with decreasing water content. Some sample present maximum strength much lower than others with comparable water content. This is due to local defaults such as air bubbles, trapped during molding, leading to stress concentration and premature failure of the sample.

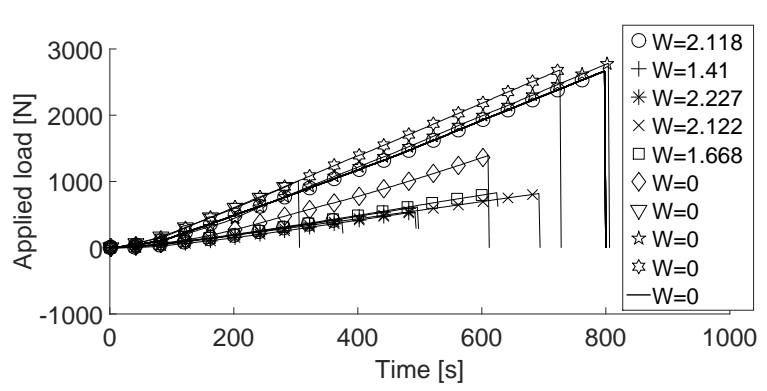

(a) Applied load vs. Time curves

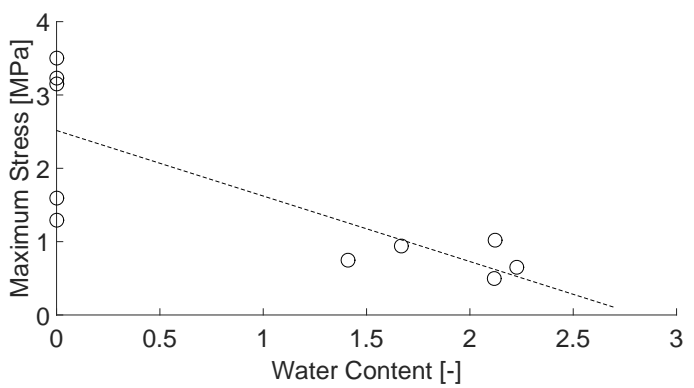

(b) Evolution of the tensile strength with water content

Figure 3: Brazilian tests results

Based on the maximum loading charge, $F_{\max }$, the tensile strength, $\sigma_{t}$, is determined using :

$$
\sigma_{t}=\frac{2 F_{\max }}{\pi D l}
$$

where $D$ and $l$ are the diameter and the length of the sample, respectively. The variation of the tensile strength with the water content is visible in Fig. $3 \mathrm{~b}$.

\section{MODEL}

RF hydrogels are considered to be an unsaturated porous medium with a solid phase, a liquid and gas phase. Within that medium, the liquid water transfers are gov- 
erned by Darcy's equation and vapor diffusion is controlled by Fick's law. Evaporation at the surface of the medium and heat transfer are calculated using the boundary layer model.

\section{Vapor and heat exchange}

The results are analyzed based on the assumption of the existence of a boundary layer all around the sample where the mass and heat transfers are assumed to take place [Kowalski (2012)]. The water flow, $\bar{q}$, from the materials to the surroundings is assumed to be proportional to the difference between the vapor density of the drying fluid, $\rho_{v, \text { air }}$ $\left[\mathrm{kg} / \mathrm{m}^{3}\right]$, and at the surface of the sample, $\rho_{v, \text { surf }}\left[\mathrm{kg} / \mathrm{m}^{3}\right]$, [Gerard et al. (2008)]. The proportionality coefficient is a mass transfer coefficient, $\alpha[\mathrm{m} / \mathrm{s}]$, characterizing the surface transfer properties. The water flow is expressed as:

$$
\bar{q}=\alpha\left(\rho_{v, \text { surf }}-\rho_{v, \text { air }}\right)
$$

The heat flux, $\bar{f}$, from the boundary to the drying air is expressed as:

$$
\bar{f}=L \bar{q}-\beta\left(T_{\text {air }}-T_{\text {surf }}\right)
$$

where $T_{\text {air }}\left[{ }^{\circ} \mathrm{C}\right]$ is the temperature of the drying air, $T_{\text {surf } f}\left[{ }^{\circ} \mathrm{C}\right]$ is the temperature at the surface of the sample, $\beta$ is a heat transfer coefficient and $L$ is water evaporation latent heat. Based on the drying kinetics, it is possible to determine the transfer coefficients (Eq. 2 and Eq. 3). The value of the drying rate during the CRP is directly linked to capacity of the drying air to evaporate the water at the surface of the porous medium and is thus linked to the value of the mass transfer coefficient. Hence, to determine the value of the transfer coefficient, the value of the drying rate during the CRP is used. Same can be said of the heat transfer: during the CRP, the temperature corresponds to the wet bulb temperature which can be analytically determined. So, no measurements of the temperature are required and only knowing the drying rate is sufficient to determine the heat transfer coefficient.

\section{Internal transfers}

The water mass balance equation is based on Richard's equation :

$$
\underbrace{\frac{\partial\left(\rho_{w} n S_{r, w}\right)}{\partial t}+\operatorname{div}\left(\rho_{w} \underline{f}_{w}\right)}_{\text {Liquid Water }}+\underbrace{\frac{\partial\left(\rho_{v} n S_{r, g}\right)}{\partial t}+\operatorname{div}\left(\underline{i}_{v}+\rho_{v} \underline{f}_{g}\right)}_{\text {Water Vapor }}=Q
$$

where $\rho_{w}\left[\mathrm{~kg} / \mathrm{m}^{3}\right]$ and $\rho_{v}\left[\mathrm{~kg} / \mathrm{m}^{3}\right]$ are respectively the water and the vapor densities, $n$ $[-]$ is the porosity, $S_{r, w}[-]$ and $S_{r, g}[-]$ are respectively the water and the gas saturation degrees in volume, $t[s]$ the time, $Q[\mathrm{~kg} / \mathrm{s}]$ is the injected flux, $\underline{f}_{w}[\mathrm{~m} / \mathrm{s}]$ and $\underline{f}_{g}[\mathrm{~m} / \mathrm{s}]$ are the water and gas phase respective macroscopic velocity and $\underline{i}_{v}\left[\mathrm{~kg} / \mathrm{m}^{2} s\right]$ is the non-advective flux of water vapor. Liquid water macroscopic velocity is given by the generalization of Darcy's law. The relative permeability and water retention curves are 
expressed using the formulation proposed by van Genuchten. The water vapor flow is assumed to follow Fick's diffusion law in a tortuous medium.

\section{Heat diffusion}

To be able to simulate the temperature evolution within the medium, the classical governing energy balance equation is used :

$$
\dot{S}_{T}+\operatorname{div}\left(V_{T}\right)-Q=0
$$

where $\dot{S}_{T}$ is the heat storage, $V_{T}$ is the heat flux and Q is the heat production term.

\section{Mechanical model}

RF hydrogel is considered as an isotropic material. Since the sample are cylindrical, an axisymmetric framework is used and allow for a simplification of the expressions. Bishop's effective stress has been chosen to describe the stress-strain relation because it directly incorporates the effect of the suction. It is expressed as:

$$
\sigma_{i j}^{\prime}=\sigma_{i j}-p_{g} \delta_{i j}+S_{r, w}\left(p_{g}-p_{w}\right) \delta_{i j}
$$

where $\sigma_{i j}^{\prime}[k P a]$ is the effective stress tensor, $\sigma_{i j}[k P a]$ is the total stress tensor, $S_{r, w}[-]$ is the water saturation and $\delta_{i j}$ is Kronecker's tensor. $p_{g}$ and $p_{w}$ denote respectively gas and water pressure $[k P a]$. The elastic strain is related to effective stress through the following relation :

$$
\sigma_{i j}^{\prime}=C_{i j k l}^{e} \epsilon_{k l}^{e}
$$

where $\sigma_{i j}^{\prime}$ is the elastic stress tensor and $\epsilon_{k l}^{e}$ is the elastic strain and $C_{i j k l}^{e}$ is Hooke's tensor. The plastic strain rate is defined through the definition of the yield criterion:

$$
f\left(\sigma_{i, j}, \epsilon_{i j}, s\right) \leq 0
$$

where $\mathrm{s}$ is the suction. The yield function needs to satisfy the consistency condition:

$$
f=\frac{\delta f}{\delta \sigma_{i, j}} \sigma_{i, j}+\frac{\delta f}{\delta s} s=0
$$

Two plastic yielding mechanisms are implemented : frictional-cohesive failure and tensile failure. They are represented respectively by the following equations:

$$
\begin{gathered}
f_{1} \equiv q-M\left(p-p_{s}\right)=0 \\
f_{2} \equiv q-3\left(p-\sigma_{t}^{\prime}\right)=0
\end{gathered}
$$


where $p_{s}$ is a parameter related to the cohesion, $M$ is a parameter defining the slope of the frictional cohesive failure in the deviatoric plane, $\sigma_{t}$ is the tensile strength, $p=$ $\sigma_{k k} / 3$ and $q=\sigma_{11}-\sigma_{33}$ are the stress invariants.

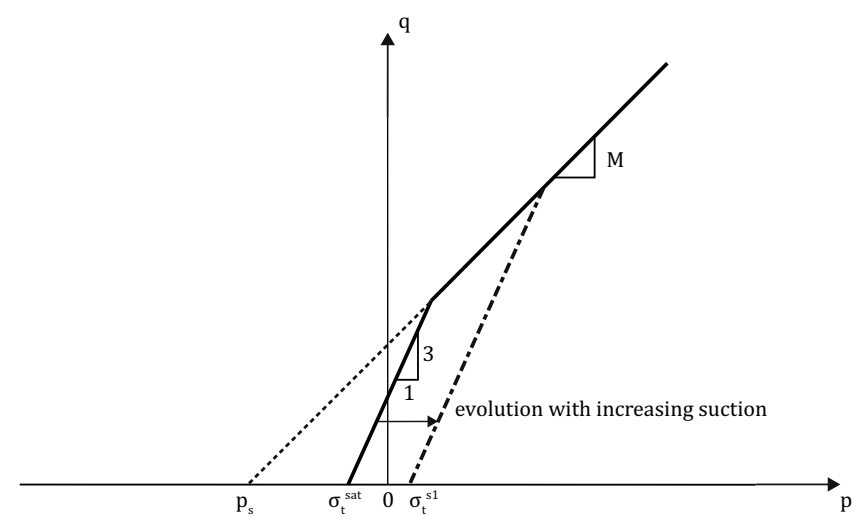

Figure 4: Yield surface

\section{Tensile failure criterion}

We propose to adopt a macroscopic criterion for tensile failure, which is a Griffith like criterion. We assume the existence of a tension cut-off expressed in terms of a minimum mean effective stress. This is a variation, expressed in terms of effective stress, of the work of Morris et al [Morris et al. (1992)]. The surface that represents this failure mechanism is expressed at equation 11 and visible in Fig. 4. When the stress path reaches the yield criterion, the sample has cracked. The uniaxial tensile strength, $\sigma_{t}$ is only dependent on suction. To take that feature into account, we use, as suggested by Péron [Péron (2008)] an exponential law of the following form :

$$
\sigma_{t}^{\prime}=\sigma_{t}^{\prime s a t}+k_{2}\left[1-\exp \left(-\frac{k_{1} s}{k_{2}}\right)\right]
$$

where $\sigma_{t}^{\text {sat }}$ is the tensile strength at the saturated state $(\mathrm{s}=0)$, namely the saturated tensile strength. The tensile failure criterion is independent from the deviatoric mechanisms. It is also assumed that the tensile failure mechanism is activated for any stress value that would reach the corresponding criterion. This may be not the case in the region close to the interception of the two mechanisms.

\section{CONCLUSION}

In this paper, the production method for RF hydrogels as well as the drying experiments methodology and data acquisition method have been briefly presented. The tools needed to analyze the drying kinetics of a sample have been introduced. Some preliminary results have been presented to exhibit the influence of the suction on the mechanical properties of the RF hydrogels. And finally, a detailed overview of the framework used to simulate the drying experiment and predict crack genesis has been given. 


\section{References}

Gerard, P., Charlier, R., Chambon, R. et Collin, F. (2008). Influence of evaporation and seepage on the convergence of a ventilated cavity. Water resources research, 44(5).

Gerard, P., LÉonard, A., Masekanya, J.-P., Charlier, R. et Collin, F. (2010). Study of the soil-atmosphere moisture exchanges through convective drying tests in non-isothermal conditions. International journal for numerical and analytical methods in geomechanics, 34(12):1297-1320.

Joв, N. (2006). Matériaux carbonés poreux de texture contrôlée préparés par procédé sol-gel et leur utilisation en catalyse hétérogène. Thèse de doctorat, Université de Liège, Belgique.

Job, N., SAbatier, F., Pirard, J.-P., Crine, M. et LÉOnARd, A. (2006). Towards the production of carbon xerogel monoliths by optimizing convective drying conditions. Carbon, 44(12):2534-2542.

KoWALSKI, S. J. (2012). Thermomechanics of drying processes, volume 8. Springer Science \& Business Media.

LÉONARD, A. (2003). Etude du séchage convectif de boues de station d'épuration-Suivi de la texture par microtomographie à rayons $X$. Thèse de doctorat, Université de Liège, Liège, Belgique.

LÉonard, A., Blacher, S., Crine, M. et JomaA, W. (2008). Evolution of mechanical properties and final textural properties of resorcinol-formaldehyde xerogels during ambient air drying. Journal of Non-Crystalline Solids, 354(10):831-838.

Léonard, A., Blacher, S., Marchot, P. et Crine, M. (2002). Use of x-ray microtomography to follow the convective heat drying of wastewater sludges. Drying Technology, 20(4-5):1053-1069.

Morris, P. H., Graham, J. et Williams, D. J. (1992). Cracking in drying soils. Canadian Geotechnical Journal, 29(2):263-277.

MusielaK, G. et JACEK, B. (2007). Non-linear heat and mass transfer during convective drying of kaolin cylinder under non-steady conditions. Transport in porous media, 66(12):121-134.

Nadeau, J.-P. et Puiggali, J.-R. (1995). Séchage: des processus physiques aux procédés industriels.

PeKala, R. (1989). Organic aerogels from the polycondensation of resorcinol with formaldehyde. Journal of Materials Science, 24(9):3221-3227.

PÉron, H. (2008). Desiccation Cracking of Soils. Thèse de doctorat, École Polytechnique Fédérale de Lausanne, Suisse. 